\title{
TERRITÓRIOS DE EXCLUSÃO. O que é possível ver de onde estamos?
}

Dinora Tereza Zucchetti $i^{(*)}$

\section{INTRODUÇÃO}

Este artigo é resultado de questões que emergiram a partir de um recorte na pesquisa 'Educação Integral entre as práticas de educação no campo social e no espaço escolar' (Capes Obeduc /Inep), ativa desde o ano de 2013. ${ }^{1}$ Elaborado tendo por base uma amostra do mapeamento da oferta do Programa Mais Educação - PME nas 54 escolas municipais de Ensino Fundamental, o texto, também, apresenta dados relativos a situações de desigualdades presentes nas escolas e no seu entorno, o que é possível de demonstrar-se por meio de um conjunto de indicadores sociais, informações oriundas dos sistemas de avaliação e gestão do Ministério do Desenvolvimento Social (MDS) e do Ministério de Educação e Cultura (MEC). Desse, através do Instituto Nacional e Pesquisas Educacionais Anísio Teixeira (INEP), são importados dados do Censo Escolar, por escola. Do MDS, as informações são oriundas do Mapa Temático de Vulnerabilidade Social - MAV (2014) referente aos beneficiários do Programa Bolsa Família (PBF), por região, na cidade.

Do ponto de vista metodológico, para a produção deste estudo, a amostra relaciona as dez (10) escolas que se destacaram por apresentar os cinco mais elevados e os outros cinco (5) mais baixos Indicadores de Desenvolvimento da Educação Básica (Ideb), tomando como base a série histórica dos anos de 2005 a 2013 e, considerando-se o mapeamento do PME da pesquisa referida. Tais indicadores, para o período, tendem a quase imobilidade apesar das ações positivas propostas pelo município, especialmente, naqueles casos em que a avaliação do INEP permanecia abaixo das metas esperadas. Fato que tornou ainda mais evidente a pertinência de perguntar sobre a interrelação de indicadores socioeconômicos e as avaliações de qualidade na educação para, a partir

\footnotetext{
${ }^{(*)}$ Possui graduação em Serviço Social pela Universidade de Caxias do Sul (1986) e doutorado em Educação pela Universidade Federal do Rio Grande do Sul (2002). É professora titular da Universidade Feevale no Programa de PósGraduação em Diversidade Cultural e Inclusão Social. E-mail: dinora@feevale.br.

${ }^{1}$ Esta investigação de natureza qualitativa estuda a implantação e consolidação do Programa Mais Educação (PME) numa cidade de médio porte, situada na região metropolitana de Porto Alegre, no Rio Grande do Sul. Interessa à investigação, sobremaneira, conhecer as questões que envolvem a realidade de escolas que ampliaram o tempo de permanência das crianças no seu interior, utilizando-se para isto, dentre outras estratégias, a oferta de projetos sociais, a abertura dos espaços físicos à comunidade nos finais de semana, bem como e, principalmente, à sua adesão ao PME. Neste sentido, vale destacar o fato do município investigado ter aderido ao PME, cujo objetivo mais imediato é a indução da Educação Integral no país, ainda no ano de 2008 quando um pequeno número de cidades acedeu ao convite em participar de uma ação proposta pelo Ministério da Educação e Cultura (MEC).
} 
deles, tecer considerações sobre as possibilidades de determinados territórios se constituírem em espaço/tempo de práticas educativas.

\section{O PME NA CIDADE: UMA QUESTÃO DE SUPERFÍCIE E FUNDO.}

O Programa Mais Educação despertou interesse investigativo a medida em que o governo federal, através da Portaria Interministerial 17, de 2007 (BRASIL, 2007), e, posteriormente, pelo Decreto-Lei 7083, de 2010 (BRASIL, 2010), propunha desenvolver atividades de ampliação da jornada escolar, nas escolas públicas. $\mathrm{Na}$ modalidade de oficinas organizadas a partir de macro campos, enquanto estratégia político-pedagógica, conforme descrito no Manual Operacional de Educação Integral (BRASIL, 2013), as ações educativas produzem um incremento nas horas que crianças e adolescentes permanecem na escola.

Atividades análogas a estas vem sendo realizadas, desde longa data, pelas políticas de assistência social através das chamadas ações socioeducativas, também denominadas de atividades de proteção social básica que, enquanto práticas de educação não escolar (MOURA e ZUCCHETTI, 2009, 2010, 2014) são realizadas, em geral, fora do espaço escolar e em turno contrário ao período das aulas.

Segundo Trilla Bernet (1998) tais práticas designam um vasto e heterogêneo leque de processos socioeducativos não escolares situados a margem do sistema oficial. Nelas, uma diversidade de temáticas são trabalhadas: apoio às aprendizagens escolares, inserção social, direitos humanos, entre outras, e, por terem uma estrutura mais flexível, têm boa penetração nas comunidades e nas próprias famílias. Em geral, resultam em maior proximidade entre instituições, sujeitos da educação e seus responsáveis; condições para a um diálogo mais profícuo e, por vezes solidário, no enfrentamento às emergências da vida.

Tais práticas, em tempos em que o acesso ao ensino fundamental não estava universalizado serviram, também, numa lógica às avessas, para acolher aqueles que não se adaptavam às rotinas das escolas. Para tanto eram oferecidas ações de socialização para garantir o acesso (não a permanência) nas escolas regulares dos que, até então, delas permaneciam excluídos, especialmente, por desconhecerem os códigos das escolas.

Do contato com práticas educativas - socioeducativos e o PME - a emergência de muitas semelhanças entre as ações. O caráter não universal; a definição de segmentos geracionais prioritários com ênfase na infância e na adolescência, em especial, àqueles que demandam por uma 
rede de proteção, governamental e não governamental. A modalidade de oficinas, entre elas, o esporte, as artes, cultura como práticas pedagógicas preferenciais; atividades realizadas por 'professores leigos', isto é, educadores (sociais), monitores, instrutores, voluntários; certa aproximação entre as intencionalidade de instituições de caráter socioeducativo e os do sistema escolar na construção de um tempo integral entre componentes curriculares e o PME, cujo conceito remonta a Darcy Ribeiro (1997, p. 476).

Só as escolas de turno integral para os alunos e professores [...] preenchem as condições necessárias indispensáveis para as crianças oriundas das classes pobres que não tiveram escolaridade prévia, progridam no estudo e completem o curso fundamental [assegurando uma] civilização letrada, dissolvendo as imensas massas marginalizadas de analfabetos.

Nesse caso, na prática, as crianças permanecem na escola por 7 (sete) horas diárias, no mínimo. No entanto, pouco se conhece sobre a existência de uma integralidade entre as oficinas e o currículo escolar mas, é sabido que a carga horária para mais, produzida com a participação das crianças na ampliação da jornada não computa carga horária no Histórico Escolar. Daí compreendermos o PME como política afirmativa que arrasta para dentro das escolas ações reconhecidas como práticas de educação no campo social onde é produzida, no mínimo, uma socialização de reposição, típica de ações de caráter compensatório.

No âmbito do município objeto da investigação, em 2013, a totalidade das escolas municipais de educação fundamental, urbanas e rurais, ofertavam práticas socioeducativas (Programa Segundo Tempo, Programa Esporte e Lazer na Cidade, Escola Aberta) que ampliavam a jornada escolar sendo que, em sua maioria, as ações eram vinculadas ao PME. ${ }^{2}$

Enquanto estratégia para a democratização do acesso à escola básica, no Ensino Fundamental, prevista na $1^{\text {a }}$ Conferência Municipal de Educação realizada no ano 2011, o município, com base também em ações socioeducativas, referendou o Pacto pela Aprendizagem: Todos temos o direito de aprender (ROCHA, 2012). Nele ficou definido os critérios para a inclusão das escolas nas chamadas ações de Educação Integrada, bem como as parcerias e as práticas interinstitucionais necessárias para a sua realização.

\footnotetext{
${ }^{2}$ Os números fornecidos pelo relatório do Consolidado do PME (2014) no âmbito da Secretaria de Educação local permitiram, por primeiro, identificar a importância da chamada Educação Integrada no município. Na cidade, entre os anos de 2008 a 2013, houve um crescimento de 582\% nas matriculas em Educação Integral. Enquanto o Censo da Educação Básica, disponível a partir de 2010, aponta o crescimento nas matriculas de educação integral nas redes públicas municipais do Ensino Fundamental, no Brasil, sendo de 163\%, a rede municipal da cidade cresceu, no mesmo período, 353\%.
} 
Entre as prioridades, as escolas cujos percentuais de reprovação, no total da matriculas, chegassem aos dois dígitos; nelas, as crianças e os adolescentes com baixo aproveitamento escolar verificado, inclusive, por sucessivas repetências. Realidade esta que orientou os encaminhamentos prioritários para a ampliação da jornada escolar que, desde o ano de 2008 e em consonância com as finalidades do PME (BRASIL, 2007 e 2010), buscam por melhorias no sucesso escolar e pela elevação no Ideb por parte de um conjunto de escolas da rede municipal cujos índices permaneciam inferiores a cinco.

Resumindo, podemos afirmar que o PME nos coloca diante da importância atribuída a outras modalidades de ações educativas, nomeadamente conhecidas como práticas de educação não escolar, entre elas, Programa e Projetos Socioeducativos. Práticas que, pouco a pouco, após o advento da doutrina da proteção integral preconizada pelo ECA passaram a compor, de forma complementar, mas nem sempre articuladas, o cenário educacional no país.

\title{
O QUE É POSSÍVEL VER DE ONDE ESTAMOS: A INDISSOCIABILIDADE DA REALIDADE SOCIAL A PARTIR DO CAMPO EMPÍRICO
}

É a partir do mapeamento do PME que se torna possível estabelecer algumas das relações a serem apresentadas nesta seção, na medida em que o Programa oportuniza visualizar a dimensão da totalidade das ações de educação integrada na cidade, bem como a extensão de um campo empírico. O referido mapeamento, como ponto de partida para esta reflexão, nos colocou diante do conceito de território, mais ainda, de tempos sociais, no sentido atribuído por Santos (2012, p. 27 e 28).

\begin{abstract}
Existe atualmente um 'controle involuntário' (ou 'não desejado') dos ritmos do espaço, desde que o tempo social, considerado como uma duração objetiva dos processos, é tão estreitamente comandado pelo Estado e pelas grandes firmas como Instituições. Este tempo das coisas comandadas pelo Estado e pelas Instituições é um exemplo do tempo empírico, já que agora o movimento da matéria obedece à disposições legais, formais, negativas - vale dizer, proibitivas - das mudanças de formas, ou positivas - ou seja, investimentos ou encorajamentos ao investimento - que, acarretam modificações na forma.
\end{abstract}

Nos territórios, de um lado, a proposição de políticas, programas, projetos com vistas a emancipação de sujeito sociais e, de outro, uma espécie de abandono, de uma falsa totalidade onde a separação, a exclusão, a marginalização é alimentada e alimenta todo um modo de produção da existência. Ou, retomando o nosso interesse reflexivo neste artigo, o que mais poderia justificar tamanha desigualdade num mesmo e "único" território, qual seja, a cidade? 
O tempo social, também tempo empírico (SANTOS, 2012) e a dimensão do território, porções de cidade, permitem melhor conhecer as idiossincrasias que, no todo ou nas partes, torna indissociáveis realidade social e o aproveitamento escolar no Ensino Fundamental considerando-se, especialmente, os resultados do Ideb. Assim sendo, tomando como referência as pontas desses indicadores como critério de inclusão das escolas, na pesquisa, passamos a nomeá-las neste artigo como sendo: escolas A,B,C,D,E para as que apresentam os maiores Ideb $(6,6$ a 7,3) e F,G,H,I,J para àquelas de Ideb mais baixos (4,4 a 5,1), tendo o indicador de 2013 como referência e, considerandose, uma sequência histórica, de repetição, desde o ano de 2005. Ver Tabela 1.

Tabela 1. Escola e distribuição do Ideb por ano

\begin{tabular}{llllll}
\hline Escola & $\begin{array}{l}\text { Ideb } \\
\mathbf{2 0 0 5}\end{array}$ & $\mathbf{2 0 0 6}$ & $\mathbf{2 0 0 7}$ & $\mathbf{2 0 0 8}$ & $\mathbf{2 0 1 3}$ \\
\hline A & 6.2 & 6.1 & 6.3 & 7.0 & 7.3 \\
B & 5.6 & 6.1 & 6.6 & 7.2 & 7.1 \\
C & 5.7 & 5.8 & 6.5 & 6.5 & 6.6 \\
D & 5.2 & 6.3 & 5.9 & 7.2 & 6.6 \\
E & 4.9 & 5.0 & 6.2 & 6.7 & 6.8 \\
F & 3.5 & 3.7 & 3.6 & 5.0 & 5.1 \\
G & 3.7 & 4.2 & 4.8 & 4.8 & 4.9 \\
H & 3.9 & 4.1 & 4.2 & 4.9 & 4.7 \\
I & - & 3.4 & 2.8 & 4.3 & 4.8 \\
J & - & 3.6 & 3.6 & 4.3 & 4.4 \\
\hline
\end{tabular}

Fonte: Elaborada pela autora a partir de dados do Inep.

De todo o modo, tais indicadores pouco dizem sobre a realidade imediata das escolas, pois é sabido que, uma avaliação externa, padronizada, definida a partir de fluxos escolares e do aproveitamento/desempenho dos alunos é sempre temerária, no sentido de conhecer o que nelas se produz (CALDERANO, BARBACOVI, PEREIRA, 2013). Daí inúmeros estudos apontarem para a dificuldade de singularizar estes indicadores na produção de uma avaliação mais consistente. Tal afirmativa não significa desconsiderar o mérito de tais mensurações que tem, em larga escala, entre os seus propósitos nortear políticas públicas no campo da educação. ${ }^{3}$ Contudo, a aproximação primeira a estas informações nos estimulou a curiosidade epistemológica no sentido atribuído por Freire (1993, p. 42) que, apurando o conceito cunhado em obras anteriores, a define como sendo: “aquela que, tomando distância do objeto, dele se ‘aproxima' com gosto e o ímpeto de desvelá-lo”.

\footnotetext{
${ }^{3}$ A exemplo do Plano de Desenvolvimento da Educação (PDE) que busca, através do Plano de Ações Articuladas (PAR) e do Fundo Nacional de Desenvolvimento da Educação Básica (FUNDEB), criar oportunidades para que as escolas negociem estratégias de melhorias diretamente com a União, visando a uma educação de qualidade para todos.
} 
Quando, no entanto, com o intuito de ampliar a compreensão de uma dada realidade optamos por olhar as escolas no seu território constatamos que, as nomeadas de A,B,C,D,E possuidoras de Ideb superior a 6 e situam-se em bairros com renda per capita mais elevada. Enquanto isto as escolas F,G,H,I,J estão situadas em bairros de menor poder aquisitivo (Tabela 2).

Tabela 2. Escola por Ideb e Renda per capta por bairro. ${ }^{4}$

\begin{tabular}{lll}
\hline Escolas & $\begin{array}{l}\text { IDEB } \\
\mathbf{2 0 1 3}\end{array}$ & per capita \\
\hline A & 7.3 & $1.088,55$ \\
B & 7.1 & 565,38 \\
C & 6.6 & 827,54 \\
D & 6.6 & 877,71 \\
E & 6.8 & 490,83 \\
F & 5.1 & 399,42 \\
G/I & 4.9 & 366,13 \\
H/J & 4.7 & 456,65 \\
\hline
\end{tabular}

Fontes: Elaborado pela autora a partir de dados do Inep e IBGE (2010).

Com base na tabela acima é importante apontar para o fato de as escolas A,B,C,D,E estão localizadas em cinco bairros distinto, o que torna possível aferir que, na cidade, a relação entre maior renda e Ideb estão melhor distribuídos. Isto porque, na outra ponta, quatro das cinco escolas ( $\mathrm{G}$ e I, H e J) estão localizadas em dois únicos bairros, os mais densamente povoados e os relativamente mais distantes do centro da cidade. ${ }^{5}$

Havia ainda mais a desvelar na busca por compreender a intrínseca relação entre desigualdade e educação escolar. A procura por esta contingência nos levou a outros indicadores sociais, no caso, aos percentuais de homicídios que atingem as populações que habitam os bairros onde estão localizadas as escolas, conforme a Tabela 3.

\footnotetext{
${ }^{4}$ Conforme dados do PNUD/IPEA a renda per capita do município, para o ano de 2010, é de 1.011,62. Disp.: <http://atlasbrasil.org.br/2013/pt/perfil_m/418\#renda>. Acesso: 25/05/2015.

${ }^{5}$ Delimitação geográfica que também permitiu a Margarete Araujo et all (2013) relacionar a criminalidade na cidade da seguinte forma: regiões da mais alta criminalidade contra o patrimônio encontram-se junto às regiões mais centrais, enquanto que, os crimes contra as pessoas concentram-se nas regiões de periferia.
} 
Tabela 3. Escola por Ideb e indicadores de violência por bairro ${ }^{6}$

\begin{tabular}{lllc}
\hline Escola & $\begin{array}{l}\text { Ideb } \\
\mathbf{2 0 1 3}\end{array}$ & \multicolumn{2}{l}{$\begin{array}{l}\text { Violência } \\
\mathbf{N}^{\mathbf{0}} \text { casos \% }\end{array}$} \\
\hline A & 7.3 & 9 & $3,54 \%$ \\
B & 7.1 & 9 & $3,54 \%$ \\
C & 6.6 & - & - \\
D & 6.6 & 3 & $1,18 \%$ \\
E & 6.8 & 19 & $7,48 \%$ \\
F & 5.1 & 16 & $6,30 \%$ \\
G/I & 4.9 & 67 & $26,40 \%$ \\
H/J & 4.7 & 49 & $19,30 \%$ \\
\hline
\end{tabular}

Fonte: Elaborado pela autora a partir de dados do Inep e do Consolidado de 2012 - SSP/RS.

Com base nas tabelas 1 e 2 podemos pensar que a desigualdade social, explicitada aqui, enquanto fenômeno que compreende a pobreza, a violência, o aproveitamento escolar pouco satisfatório, o uso do espaço urbano, entre outros, é mais facilmente localizável. Dimensão que é histórica porque, segundo Bauman (1999, p. 16 e 18), desde o pós-guerra a mobilidade é o "fator de estratificação mais poderoso e cobiçado [uma vez que] o capital pode sempre se mudar para locais mais pacíficos se o compromisso com a 'alteridade' exigir uma aplicação dispendiosa da força ou negociações cansativas". Mediante tal extraterritorialidade da elite, afirma Bauman (op.cit.), nos vemos diante da territorialidade forçada dos demais.

Em realidade, estamos diante da complexidade da sempre divisão do trabalho que, mesmo na dita modernidade tardia ou líquida, nos mantem prisioneiros da "mais representativa das objetivações da sociedade" (SANTOS, 2012, p. 33). Daí o título do artigo e nele a hipótese de que há dados suficientes para pensarmos em territórios de exclusão quando são acrescidos fatores socioeconômicos mais específicos e/ou melhor relacionados à realidade que ser pretende demonstrar. E, neles há escolas que, todo o dia, enfrentam as adversidades do seu entorno buscando por interferir nestes espaços/tempos de exclusão, a exemplo, do que propõe o PME. Entretanto, nem sempre isto produz efeitos de curto prazo.

É o caso dos indicadores sobre a violência que nos permitem verificar um novo e desolador fato. Nos dois bairros, de menor renda per capta, onde se localizam as escolas G/I e H/J, o número

\footnotetext{
${ }^{6}$ Os indicadores são resultado do Consolidado do SSP/RS de 2012 e identifica os homicídios consumados e as tentativas que totalizam 254 ocorrências no ano.
} 
de adolescentes e jovens (tomando como ponto de corte a idade entre 13 e 24 anos) envolvidos em delitos de homicídio é maior do que em todos os demais bairros da cidade.

Quando se olha, exclusivamente, para os dados destes territórios, buscando identificar se os jovens infratores são vítimas ou autores dos homicídios, a realidade se apresenta com uma diferença importante. No bairro onde localizam-se as escolas H/J, em sua maioria, os jovens são vítimas de crimes tipificamos como homicídios (consumados ou não). Ver gráfico 1.

Gráfico 1. Indicadores de violência (tentativas de homicídios e homicídios consumados) num bairro.

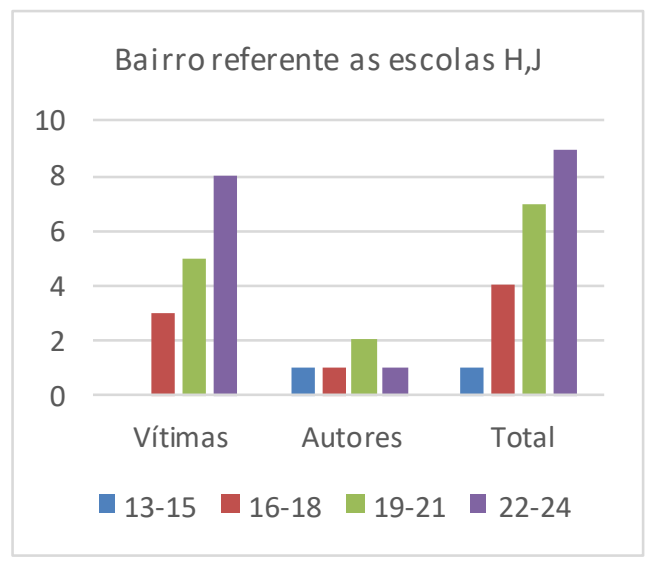

Fonte: Elaborado pela autora a partir de dados do Consolidado de 2012 - SSP/RS

Enquanto isso, a realidade demonstrada no Gráfico 2 é ainda mais desalentadora. No bairro onde se situam as escolas G/I os dados colocam ainda mais em xeque o modelo de humanismo que sustenta nosso modo de viver em sociedade. Não bastasse o incremento dos números onde os jovens são autores dos homicídios e/ou de tentativas de homicídios é entre os mais jovens, aqueles com idade de 13 a 15 anos, que os indicadores são mais elevados.

Gráfico 2. Indicadores de violência (tentativas de homicídios e homicídios consumados) num bairro.

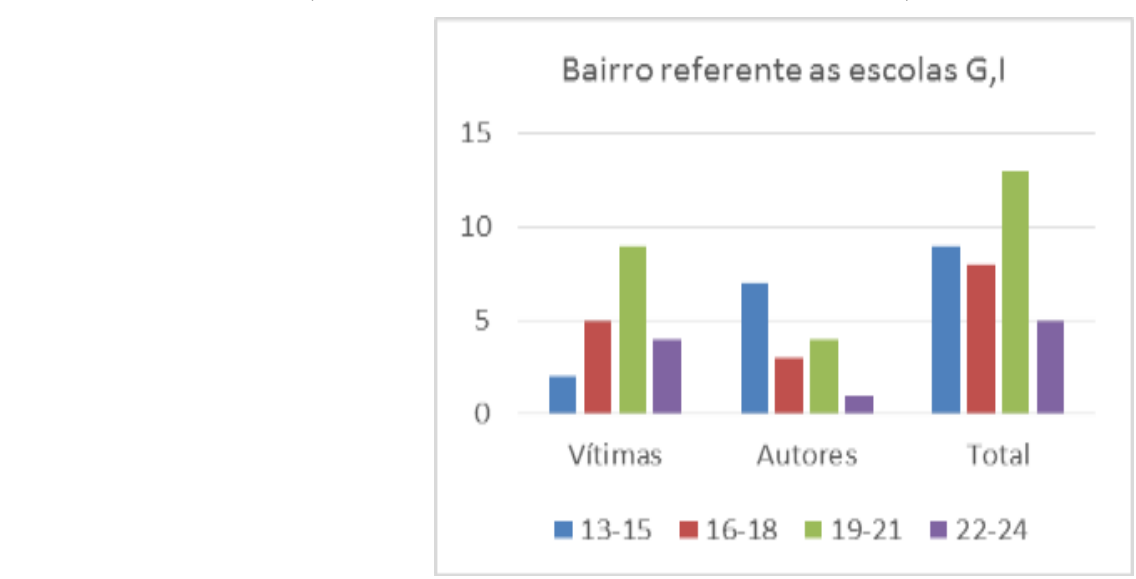

Fonte: Elaborado pela autora a partir de dados do Consolidado de 2012 - SSP/RS 
Situação que se vê agravada, conforme o Consolidado da Secretaria de Segurança Pública do Estado do Rio Grande do Sul - SSP/RS (2012), quando demonstra que os jovens de 15 anos residentes neste bairro são reincidentes. Isto é, todos eles ou cumpriam medida socioeducativa e/ou delas eram egressos quando do levantamento realizado. Para piorar ainda mais esta assustadora realidade que é na mesma medida complexa, no que refere a infância e a adolescência, evidencia-se que os altos índices de violência entre os jovens está relacionado ao tráfico de drogas em $80 \%$ dos casos. Hentz (2014) afirma que acertos de contas e disputas por territórios, fazem do narcotráfico a causa do crescimento da violência.

\section{POLÍTICAS SOCIAIS: A IMPORTÂNCIA DA INTERSETORIALIDADE ENTRE ALENTOS E CONTRADIÇÕES.}

Mesmo diante de dados tão alarmantes é possível identificar situações nas quais as políticas sociais, principalmente no que tange a perspectiva da intersetorialidade, produzem certo alento e/ou acerto no sentido de focar na proteção dos mais vulnerabilizados socialmente. A ideia de intersetorialidade é tomada aqui como um ponto importante para a reflexão pretendida neste texto, uma vez que é base da concepção e da gestão do PME, ação política que torna possível as relações aqui realizadas.

A intersetorialidade - jovem senhora no âmbito da gestão pública - também se configura como importante estratégia do executivo local quando coloca a Educação Cidadã como perspectiva para a rede de ensino em questão. Através do Pacto todos temos o Direito de Aprender (ROCHA, 2012) é prevista a valorização e a formação continuada de professores entre as ações para melhorar a qualidade do ensino.

Sendo assim, a intersetorialidade representa por parte dos entes públicos uma aposta na gestão compartilhada de políticas públicas que, em âmbito federal, juntamente com a municipalização das políticas sociais e o protagonismo dos Conselhos Municipais obrigam planejamentos comuns para ações voltadas aos mesmos segmentos populacionais. Não isenta de contradições a intersetorialidade permite que setores distintos colaborem entre si na busca por consolidar metas previamente estabelecidas.

Exemplo disso é o planejamento realizado para intervir sobre os altos índices de repetência que, no ano de 2007, alcançavam dois dígitos (10,39\%) nas escolas municipais de Ensino Fundamental e, para os quais o PME, supunha, viria contribuir na redução, conforme o Documento Escola Cidadã (ROCHA, 2012). Neste caso, as Secretarias Municipais de Assistência Social e de 
Saúde somam-se à de Educação construindo uma articulação entre a redes de proteção e de ensino (numa experiência, quiçá, inédita de interlocução) na realização de encaminhamentos diversos nas áreas da saúde, saúde mental, geração de trabalho e renda, entre outros. Conjuntamente, buscam o enfrentamento de questões tidas, historicamente, como afetas somente à educação, a exemplo da melhoria dos índices de evasão e repetência, numa tarefa que exemplifica a intersetorialidade nas políticas públicas.

Desta feita, entre 2007 e 2013 os indicadores de aproveitamento escolar passaram a oscilar positivamente nas escolas pesquisadas. Tornou-se possível identificar uma redução média, em torno de $50 \%$, na reprovação naquelas instituições cujos percentuais eram mais elevados. Sem maiores questionamentos, vê-se cumprir, documentalmente, a meta proposta pelo Plano Municipal para este quesito.

A intersetorialidade também é questão central na gestão do PBF, política social alinhada ao controle de frequência escolar mínima para as crianças e os jovens beneficiários do Programa que, entre outras ações, fazem dialogar as políticas sociais. Importante lembrar que, no Brasil, mesmo timidamente, as políticas sociais historicamente imprimiram condicionalidades entre o acesso à benefícios e uma certa contrapartida para os usuários. No caso do PBF é fator preponderante, reproduzindo de forma mais efetiva os contratos de ajustes do Banco Mundial, quando do ajuste estrutural nos anos de 1970 e 1980, até os dias de hoje (DEITOS, 2010).

Assim sendo, na perspectiva do enfrentamento às desigualdades sociais, a presença do PBF merece destaque positivo no cenário em questão. Também, porque, no município, a maior densidade de distribuição de renda condicionada ocorre, exatamente, nas regiões de maior pobreza identificadas, anteriormente, como sendo aquelas onde se localizam as escolas de menor Ideb (G/I e J/H). Realidade que também é possível de ser demonstrada no Mapa Temático da Vulnerabilidade Social Social, do MDS, abaixo. 
Figura 1. Localização das escolas na distribuição dos domicílios particulares permanentes beneficiários do PBF.

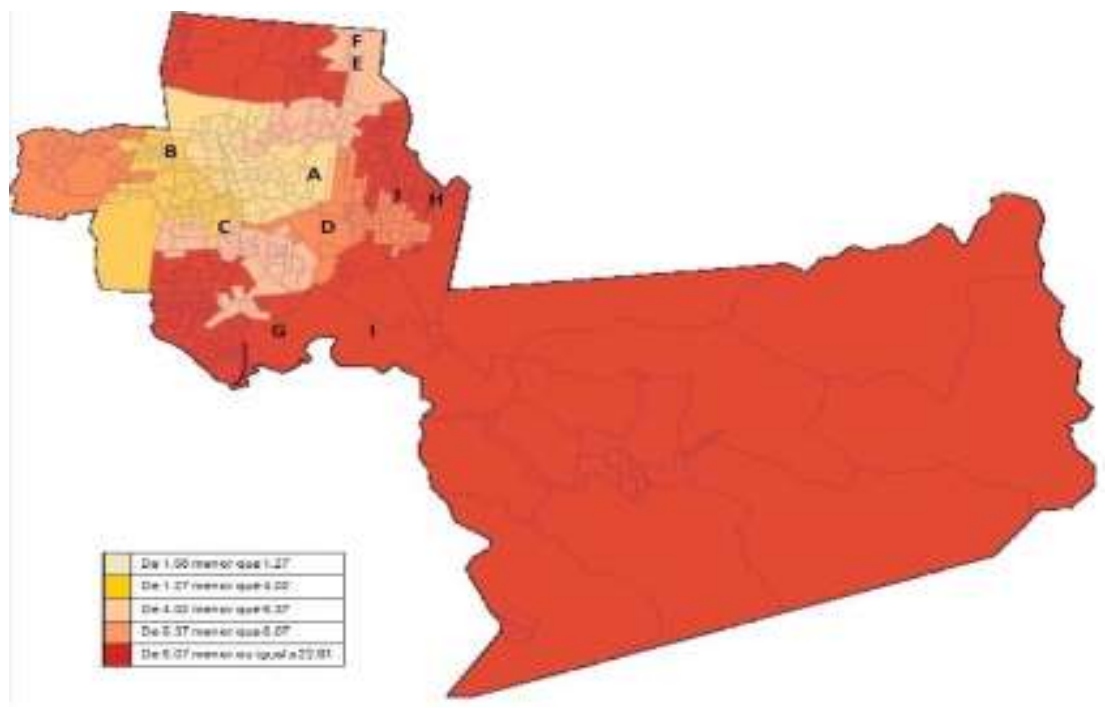

Fonte: Adaptado pela autora a partir do Mapa Temático da Vulnerabilidade Social Social - MDS, 2014.

Ainda sobre o impacto do PBF entre os beneficiários, Svoboda (2014) chama a atenção para o fato de que a distribuição de renda além de focar nos piores situados socialmente impacta, de fora positiva, na melhoria do processo de escolarização dos filhos. Estes passam a ir para escola com frequência, melhor alimentados, com vestimentas adequadas às variações climáticas, empunhando materiais escolares nunca antes acessados. As mães dizem que recebem o Bolsa Família por causa dos filhos e afirmam que, em função disto, o recurso financeiro deve reverter, primeiramente, em benefícios para eles. Segundo o autor estes são alguns dos resultados da pesquisa realizada e que tem como sujeitos da investigação na sua maioria mulheres, mães, moradoras dos bairros onde estão situados as escolas G/I e J/H da cidade em questão. ${ }^{7}$

Entretanto, quando se retorna aos propósitos do PME, suas positividades na relação que estabelece com outras políticas de proteção social, tanto quanto a sua abrangência no município, não é possível, neste artigo, deixar de apontar para um elemento contraditório presente na sua execução, no âmbito local. Quando investigamos mais profundamente o modo como as matriculas em educação integral estão distribuídas - considerando-se as definições previstas no Pacto pela Aprendizagem: Todos temos o direito de aprender (ROCHA, 2012) - verifica-se que, embora o documento enfatize que demandam por mais tempo de escola os moradores de territórios marcados

\footnotetext{
${ }^{7}$ Realidade que, segundo o autor, reforça e justifica o PBF em consonância com Rego e Pinzani (2013, p. 11 e 12), embora, estas, reiterem os limites do referido Programa. "A pobreza é um problema complexo e, como tal, não admite uma solução fácil. Portanto, não pode ser resolvida simplesmente por um programa de transferência de renda, como o Bolsa Família [...]. Contudo, tal programa enfrenta importantes questões ligadas à pobreza, oferecendo-lhes uma resposta pelo menos parcial; melhor ainda, lida com algumas de suas facetas", afirmam.
} 
pela pobreza e violência e, nesses, os que apresentam baixo aproveitamento escolar - observa-se que o número de matriculas no PME é relativamente mais expressivo em regiões tidas como de menor vulnerabilidade social e maior renda per capta. Retomando e dizendo de forma ainda mais clara, a maior concentração de matriculas do PME, na cidade, está entre as escolas de Ideb superior. Ver tabela 4. Fato que, certamente, pode dificultar a problematização sobre o impacto do PME na redução da repetência e/ou melhoria no aproveitamento escolar, um dos objetivos institucionais do Programa. E, mesmo que esta questão não seja tratada de forma direta, neste texto, é fato que tal reflexão tem sentido e pertinência nas avaliações do PME, tanto nos níveis micro quanto macro.

Tabela 4. Percentual de matriculas no PME nas escolas por ano

\begin{tabular}{|c|c|c|c|c|c|c|}
\hline \multirow[t]{2}{*}{ Escola } & \multirow{2}{*}{$\begin{array}{l}\text { IDEB } \\
2013\end{array}$} & \multicolumn{5}{|c|}{$\mathrm{N}^{\mathrm{o}}$ matriculas Mais Educação/ano } \\
\hline & & 9 & 10 & 11 & 12 & 13 \\
\hline A & 7.3 & & & & & $28 \%$ \\
\hline $\mathrm{B}$ & 7.1 & & & & $31 \%$ & $51 \%$ \\
\hline $\mathrm{C}$ & 6.6 & & & & & $23 \%$ \\
\hline $\mathrm{D}$ & 6.6 & & & $37 \%$ & $35 \%$ & $37 \%$ \\
\hline $\mathrm{E}$ & 6.8 & $59 \%$ & $59 \%$ & $71 \%$ & $52 \%$ & $47 \%$ \\
\hline $\mathrm{F}$ & 5.1 & $13 \%$ & $13 \%$ & $13 \%$ & $10 \%$ & $13 \%$ \\
\hline $\mathrm{G}$ & 4.9 & & & $25 \%$ & $17 \%$ & $23 \%$ \\
\hline $\mathrm{H}$ & 4.7 & $19 \%$ & $20 \%$ & $21 \%$ & $21 \%$ & $21 \%$ \\
\hline I & 4.8 & $11 \%$ & $11 \%$ & $12 \%$ & $10 \%$ & $11 \%$ \\
\hline $\mathbf{J}$ & 4.4 & $20 \%$ & $21 \%$ & $21 \%$ & $23 \%$ & $24 \%$ \\
\hline
\end{tabular}

Fonte: Elaborado pela autora a partir de dados do Consolidado do PME 2012 - Smed.

Por último, seguindo a tentativa de pensar as políticas sociais, seus programa e projetos enquanto ações que intervém nas necessidades de proteção social dos piores situados socialmente, merece destaque os dados do Relatório sobre a distribuição de Organizações Não Governamentais ONGs na cidade. A partir de uma pesquisa realizada pela Universidade local, no ano de 2012, e tendo como informantes as equipes diretivas das escolas públicas e privadas do Ensino Fundamental da cidade, foram reconhecidas 19 instituições de proteção à criança e adolescente.

Tal identificação nos permite inferir sobre a oferta de serviços de proteção social que, em geral, servem de apoio às escolas no que tange ao cuidado de seus alunos, em consonância com o Estatuto da Criança e do Adolescente - ECA (Tabela 5). 
Tabela 5. Número de Organizações Não Governamentais (ONGs) por bairro

\begin{tabular}{ll}
\hline Bairro & $\mathbf{N}^{\mathbf{0}}$ Ongs \\
\hline Centro & 5 \\
H J & 2 \\
A & 2 \\
E & 2 \\
D & 1 \\
Outros & 7 \\
Total & 19
\end{tabular}

Fonte: Elaborada pela autora a partir de dados de Relatório do Conselho Municipal da Criança e do Adolescente - 2012

Interessante observar que na distribuição por bairro a maioria das ONGs, 17 delas, situam-se na área central e nos bairros próximos ao centro da cidade. Chama a atenção, também, que no bairro das escolas G, I não há referência a existência de ONGs e somente duas instituições estão localizadas entre os 3 bairros de maior vulnerabilidade social. ${ }^{8}$ A contradição, aqui, está exatamente na localização das ONGs que nem sempre estão situadas nos bairros de maiores demandas sociais. Ou, numa outra possível interpretação, considerando-se os informantes da pesquisa, gestores de escolas da rede municipal de ensino: o não reconhecimento da existência de organizações não governamentais nas proximidades das escolas, de alguma forma, explicita a precária articulação entre as instituições (escolas e ONGs) enquanto recurso à parceirização, necessário a proteção das crianças e jovens adolescentes?

\section{À GUISA DE ENCERRAMENTO}

Este artigo congrega e apresenta um conjunto de indicadores educacionais e socioeconômicos para explicitar determinadas (categorias de) realidades que incidem sobre a vida e o aproveitamento escolar de crianças que frequentam a rede pública de ensino. Entendemos, estar demonstrando o quanto dados estatísticos relativos a vida de pessoas que habitam determinados territórios não podem estar dissociados, entre si, quando na leitura de contextos mais amplos. Neste sentido, identificamos uma relação imediata entre as realidades evidenciadas, aquilo que se apresenta diante de nós e as facilidades e/ou limitações vividas por famílias, grupos, comunidades.

Indicadores de renda, violência e criminalidade, aproveitamento escolar, matriculas em jornada escolar ampliada, entre outros, compartilham de uma mesma lógica, qual seja, a que nos

\footnotetext{
${ }^{8}$ É sabido que, em geral, tais territórios contam com a presença das Organizações Governamentais, em especial, as de assistência social. Tendo a cidade aderido a municipalização da política de assistência, a presença dos Centro de Referência de Assistência Social (CRAS) e suas ações de proteção social básica são pontos de referência local, de reconhecimento e apoio familiar (SVOBODA, 2014).
} 
permite melhor identificar, neste caso, sujeitos da educação que socializam experiência de desigualdade social. Realidade que explicita infâncias vividas de formas diversas por crianças e adolescentes que habitam uma mesma cidade.

O que, por sua vez, põe em suspenso uma série de construções discursivas predominantes, entre elas, as que versam sobre o aproveitamento escolar em relação as avaliações de larga escala quando dissociadas da realidade. Fato que coloca em relevo, geralmente, a culpabilidade de professores, alunos e famílias sobre tais resultados. Exemplo disto nos é trazido por Calderano, Barbacovi e Pereira (2013) ao advertir sobre as consequências que a utilização do Ideb produz sobre o que chama de chão das escolas, advertindo, especialmente, às realidades que o indicador não considera. Para a pesquisadora, torna-se impossível apontar singularidades de instituições escolares mediante tais indicadores quando analisados de forma isolada. Os dados apresentados, neste texto, são a mais fiel expressão do exposto.

Quando são demonstradas as contradições e dissonâncias que emergem da crueza da realidade social, passamos a ter elementos concretos para problematizar de forma qualitativa a efetividade de políticas assistenciais e/ou educativas voltadas a segmentos populacionais desfavorecidos. Daí o que resta é reiterar a complexidade dos fenômenos que envolvem os territórios, em especial, aqueles que se encontram em desvantagens diante dos melhor situados, menos degradados e com renda per capta mais elevada.

Por sua vez, impossível não reafirmar neste contexto, a exemplo do que vem sendo dito por pesquisadores brasileiros que, no caso do Ideb tais índices se emprestam mais para referendar as realidades que avalia do que para gerar produção de conhecimento a partir do que identifica. Sequer, muitas vezes, são utilizados para garantir ações afirmativas que venham contribuir para impactar positivamente, não somente, as instituições escolares mas os recursos que favorecem as aprendizagens dos alunos/as. Exemplo disto é o recurso do Programa Dinheiro Direto na Escola PDDE, assistência financeira suplementar que, entre outros, via Programa Mais Educação transfere recursos financeiros, considerando as matriculas em educação integral.

Da mesma forma urge que as políticas sociais incidam com efetividade sobre as realidades de exclusão e, impactem, verdadeiramente, os indicadores. É o Programa Bolsa Família que se apresenta como um exemplo neste sentido. Desde 2011, o MDS busca fortalecer ainda mais a relação entre condicionalidades e transferência de renda. Por exemplo, as escolas em que mais da metade dos estudantes são beneficiários do PBF - denominadas “Escolas Maioria PBF" -, são tidas como prioritárias no processo anual de adesão ao PME. 
Para além de reafirmar que condições de infraestrutura, adequação e segurança das construções, manutenção predial com acessibilidade, permanência de professores, realidade socioeconômica das famílias, acesso a bens e serviços, existência de equipamentos sociais de proteção e promoção da cidadania no entorno da escola, entre outros, incidem e interferem diretamente sobre estas e sobre o aproveitamento escolar, faz-se necessário retornar ao Programa Mais Educação.

Neste sentido vale reafirmar, também, a expressão positiva que o PME e as demais modalidades de práticas socioeducativas produzem no quesito aproximação de atores até então distantes da escola - famílias, jovens, lideranças comunitárias, motivadores culturais - que, ao adentrar os espaços e os tempos escolares, servindo-lhes de apoio, levam para a escola a preocupação com a proteção social dos seus. Há um sentido integrador na escola de tempo integral (BRASIL, 2007), nem por isso é possível atribuir tamanha responsabilidade ao Programa e à escola que oferece educação integral sentido que remeta à expressão território educativo.

Mesmo em épocas em que se avizinham cortes no orçamento da União, resultado da recente crise política e econômica brasileira, o PME continua permitindo abrir a escola para o seu exterior e, desta forma, dar visibilidade a uma relação pouco ou quase nunca explorada, qual seja, a imbricada relação entre educação, sociedade e desigualdade.

Tal tríade torna possível verificar o quanto histórias de fracasso escolar, entre outras experiências de integração subordinada, no sentido atribuído por Santos (1999) resultam de um emaranhado de fios difíceis de desvelar. Nelas, o território, em seu sentido proibitivo, tal qual entendido por Santos (2012), pouco permite relacionar os impactos positivos da educação escolar no entorno de onde esta se realiza.

Como se pode, a partir de um determinado lugar, porção de cidade demasiado violento, carente de recursos sociais, sucateado em infraestrutura, depositar-se na escola a proposição de transforma-se em território educativo, recuperando o ideário do movimento das cidades educadoras da Unesco, de 1990. Faz-se, outrossim, indispensável considerar-se, minimamente, as condições objetivas para tal.

Somente uma leitura demasiado positiva, míope até, acerca de realidades sociais altamente precarizadas e vulnerabilizadoras poderá, objetivamente, vislumbrar cidades, territórios, enquanto espaços educativos. É isto que temos visto de onde estamos. Uma realidade mais ampla, no âmbito da cidade, que se mostra altamente contraditória, onde oscilam praticas educativas oferecidas em 
boas condições de infraestrutura escolar, localização privilegiada considerando-se renda e recursos de proteção social. De outra parte, o seu oposto. Precarização de toda a ordem e que dizem da necessidade de, cada vez mais, se buscar estratégias de estudo e análise que aproxime as áreas da educação a da sociologia. Revigorando os estudos da Sociologia da Educação.

Dito isto, afirma-se ser possível desvelar uma realidade somente a partir de um conjunto articulado de dados. Indicadores sociais, isoladamente, não demonstram e sequer favorecem o reconhecimento do sentido histórico presente em territórios, em especial, naqueles mais vulnerabilizados socialmente. Por fim, reiterar também que, análises de práticas educativas isoladas, centradas em aprendizagens individualizadas, desvinculadas do desenvolvimento das comunidades, também, não produzem efetividades social. 


\section{REFERÊNCIAS}

ARAUJO, Margarete P. et al. Metodologia de mapeamento para criminalidade: estudo de caso do município. Revista Brasileira de Gestão e Desenvolvimento Regional. Taubaté, SP, v. 9, n. 3, p. 279-291, set.-dez. 2013.

BAUMAN, Zygmunt. Globalização e as consequências humanas. Rio de Janeiro: Zahar. 1999.

BRASIL. Decreto 7.083, de 27 de janeiro de 2010. Dispõe sobre o Programa Mais Educação. Disp,: <http://www.planalto.gov.br/ccivil_03/_ato2007-2010/2010/decreto/d7083.htm> Acesso: 22 jun. 2015.

Portaria Normativa Interministerial 17, de 24 de abril de 2007. Disp.: <http://portal.mec.gov.br/ arquivos/pdf/mais_educacao.pdf>. Acesso: 22 jun. 2015.

Manual Operacional de Educação Integral 2013. Disp.: <http://portal.mec.gov.br/index.php?option=com docman\&task=doc download\&gid=14458\&Itemid=>. Acesso: 22 jun. 2015.

CALDERANO, Maria A.; BARBACOVI, Lecir J.; PEREIRA, Margareth (Orgs.). O que o IDEB não conta? Processos e resultados alcançados pela escola básica. Juiz de Fora: Editora UFJF, 2013.

CONSELHO MUNICIPAL DA CRIANÇA E DO ADOLESCENTE. Pesquisa crianças e adolescentes. Novo Hamburgo: Universidade Feevale/CPP. 2012.

DADOS CONSOLIDADOS DO PROGRAMA MAIS EDUCAÇAO 2014. Secretaria Municipal de Educação. Dados de Uso Restrito. 2014.

DEITOS, Roberto A. Politicas públicas e educação: aspectos teórico-ideológicos e socioeconômicos. In: Acta Scientiarum. Education. Maringa, v. 32, n. 2, p. 209-218, 2010.

DADOS CONSOLIDADOS 2012. Secretaria Estadual de Segurança Pública. Estado do Rio Grande do Sul. Dados de Uso Restrito. 2015.

FREIRE, Paulo. Professora, sim; tia, não: cartas a quem ousa ensinar. São Paulo: Olho D’Agua, 1993.

HENTZ, Tatiana. Vizinhos da violência clamam por segurança. Disp.: <http://www.jornalnh.com.br/index.php?id=/ noticias/regiao/materia.php\&cd_matia=49603\&dinamico=1 Acesso: 14 dez. 2016.

MOURA, Eliana P. G.; ZUCCHETTI, Dinora T. Educação Não Escolar, Universidades e Educação Popular: horizonte de novos desafios. Educação Unisinos, vol. 13, n. 02, p. 125-134, mai.-ago. 2009.

; ZUCCHETTI, Dinora T. Educação além da escola: acolhida a outros saberes. Cadernos de Pesquisa, vol. 40, n. 140 , p. 629-648, mai.-ago. 2010.

; ZUCCHETTI, Dinora T. Socialização escolar, educação não escolar e (con)formação de sujeitos. Contrapontos, vol. 14, n. 02, p. 339-352, mai.-ago. 2014.

REGO, Walquíria Leão; PINZANI, Alessandro. Vozes do Bolsa Família: autonomia, dinheiro e cidadania. São Paulo: Ed. Unesp, 2013.

RIBEIRO, Darcy. O Testemunho. São Paulo: Siciliano, 1997.

ROCHA, Silvio. (Org.). Escola Cidadã: participação qualidade e aprendizagem. s.e. 2012.

SANTOS, Milton. Pensando o espaço do Homem. São Paulo: Editora da USP, 2012.

SANTOS, Boaventura S. A Construção Multicultural da Igualdade e da Diferença. Oficina do CES, n. $135,1999$. Disp.: <http://www.ces.uc.pt/publicacoes/oficina/135/135.pdf>. Acesso: 11 jan. 2016.

SVOBODA, Christian. O programa bolsa família no dito popular 'assim de pobre'. 2012. 104 f. Dissertação (Mestrado em Diversidade Cultural e Inclusão Social) - Feevale, Novo Hamburgo, RS, 2014. Disp.: <http://biblioteca.feevale. br/Dissertacao/DissertacaoChristianSvoboda.pdf>. Acesso: 10 junho 2015

TRILLA, Bernet. La educación fuera de la escuela. Ámbitos no formales y educación social. Barcelona: Ariel, 1998. 


\section{RESUMO}

Resultado de pesquisa mais ampla o artigo parte do mapeamento da oferta do Programa Mais Educação PME, numa cidade da região metropolitana de Porto Alegre/RS, buscando relacionar desigualdade social e educação. Recorta um conjunto de 10 escolas considerando-se o Índice de Desenvolvimento da Escola Básica - Ideb e, com base em indicadores socioeconômicos, evidencia realidades sociais presentes no entorno de escolas. Dados quantitativos explicitam a violência entre jovens, a renda familiar, a (in)existência de instituições de proteção, entre outros, tornando possível identificar o quanto territórios, lócus de fazer sociedade, podem ser transformados em espaços/tempo de exclusão.

Palavras-chave: Território. Desigualdade. PME. Ideb.

\section{TERRITORIES OF EXCLUSION. WHAT CAN WE SEE FROM WHERE WE ARE?}

\section{ABSTRACT}

Presenting the results of qualitative research, the article takes the mapping from the More Education Program in a city in the greater Porto Alegre/RS region as a reference point. It selects a set of 10 schools, taking the Basic School Development Index into account and, based on socioeconomic indicators, exposes the situations of inequality present in the school environment. Violence, low incomes and the (non)existence of law enforcement are considered factors that reveal how much territories, the place where society is formed, can be transformed into spaces/times of exclusion.

Keywords: Territory. Exclusion. SME. Ideb.

Submetido maio 2016 Aprovado ago. 2016 